\title{
A new look at population change and regional development in Aotearoa New Zealand
}

\begin{abstract}
In New Zealand, population change is interlinked with regional development. Places growing in population attract regional investment, while regional investment—or lack thereof — can change migration patterns. However, to determine the appropriate response to population change for a community, it is important to understand that population change involves much more than 'just' migration. Specifically, it involves interactions between the three components of population change: natural change (births minus deaths), net migration (international and internal), and population ageing (changing cohort size). For example, migration can be negative, but growth can be positive due to underlying natural increase or growth in cohort size. Responses need to differ, depending on these drivers. The goal of this paper is to provide new insights into these interactions using data for 275 cities, towns and rural centres (hereafter 'urban places') in New Zealand for the period 1976 to 2013. The results show that natural change has been consistently positive for most urban places up to the present, although projections indicate that in the future this component will become negative across much of the country. At the same time, net migration shows considerable spatial variation, not only in terms of volume, but also direction (negative or positive), which differs markedly by age. A net gain of people of retirement age can offset a net loss of young adults to deliver overall growth, and vice-versa, but the two have very different implications for longer term growth. An analysis of the drivers of net migration using GIS and machine learning techniques provides an indication of the importance of economic conditions (landuse and access to markets), lifestyle, access to essential services (hospitals and education), and their interaction with age in regional change. The results show that population age is the best predictor of migration. Younger people are moving to cities for tertiary education and work and older people near or in retirement are moving to smaller lifestyle towns but also want to be close to amenities such as hospitals and international airports. The research also shows that natural lifestyle characteristics (landscape and climate), in combination with age are just as important as economic conditions for understanding migration. Regional development, such as infrastructure that helps business (ports and services) is important for the working age population but not necessarily the retirement age group. When regional development, age/life-cycle stage and lifestyle come together, such as in Queenstown and Tauranga, net migration gain is high.
\end{abstract}

\section{Introduction}

Population change can have a substantial impact on communities, both when there is decline and growth, and understanding what is driving these changes can help with population forecasting and associated planning. Understanding regional change in New Zealand and evaluating prospects for regional development has traditionally focused on economic and social conditions, and this is the emphasis discussed in other papers in this special issue. In this paper, the focus is on the demographic realities and changes, and the drivers of net migration. The media is full of stories of urban places which are struggling to maintain a viable population and there is closing of schools and important services. Solutions for these 
urban places have not been encouraging for locals - "managed decline" can hasten decline (McMillan, 2016), and “zombie town” (Equab, 2014) has become an unhelpful label of many places experiencing growth challenges. Conversely there are stories of urban places where population growth is high and there is pressure on infrastructure and house prices. In this paper, we argue that it is critical to understand the type of population change (i.e., the local 'drivers') being experienced by each place, so that there can be an adequate policy response. Is population change being driven mainly by natural change (births minus deaths), net migration (internal and/or international), or cohort change (large cohorts replacing smaller ones and vice-versa), and/or in particular combinations? If natural change or cohort change are concealing underlying net migration loss, or vice-versa, what are the implications for longer term growth? And where net migration is a major factor contributing to population change, why are people moving to different places? Is it jobs, lifestyle, and/or access to essential services? Both the age of migrants and the local population age structure are crucial to these interactions, because gains at one age can offset losses at another, and vice-versa (Jackson 2016; Jackson and Brabyn 2017). Regional development initiatives first need to carefully consider local age profiles and the characteristics of places that are attractive to different age groups.

A conceptual diagram of population change is illustrated in Figure 1. This diagram is in the spirit of a number of general population change diagrams e.g. see Myrdal in Hagget (1983); however, here we focus more on the demographic drivers. The Figure shows how age interacts with both natural population change and net migration. The aim of this paper is to illustrate and substantiate the relative importance of these components using census data, demographic modelling, and spatial analysis of place in New Zealand (NZ). Several research projects are drawn on, including a NZ Royal Society Marsden-Funded programme entitled; "The subnational mechanisms of the ending of population growth: Towards a theory of depopulation”, and an Ministry of Business Innovation and Enterprise (MBIE) project titled "Capturing the Demographic Dividend for Aotearoa NZ" (CaDDANZ). The former project involved analysis of population census data and GIS social and environmental data to explain the interaction of natural population change, ageing and migration, as well as to produce a spatial model of net migration. An output of the CaDDANZ project is the NZ Atlas of Population Change (socialatlas.waikato.ac.nz) which provides maps and graphs at a range of scales - urban, Territorial Authority Area (TA), and Regional Council (RC) to illustrate the drivers of New Zealand's subnational population change. Both projects use an urban places data set that includes every NZ city, town, and rural centre $(n=275)$, based on Statistics New Zealand's (2019) current definition of urban areas and rural centres ${ }^{\mathrm{i}}$, and was compiled using and modelling data from every population census between 1976 and 2013 (37 years) ${ }^{\text {ii }}$. Rural centres are communities or settlements but we use the phrase rural centre to distinguish from communities in large cities and to emphasise the close relationship with the surrounding rural areas. This data set was supplemented with environmental and social data using GIS, and machine learning was used to determine the relative importance of the different drivers of net migration, such as employment, lifestyle and access to essential services such as hospitals, airports and tertiary education. 


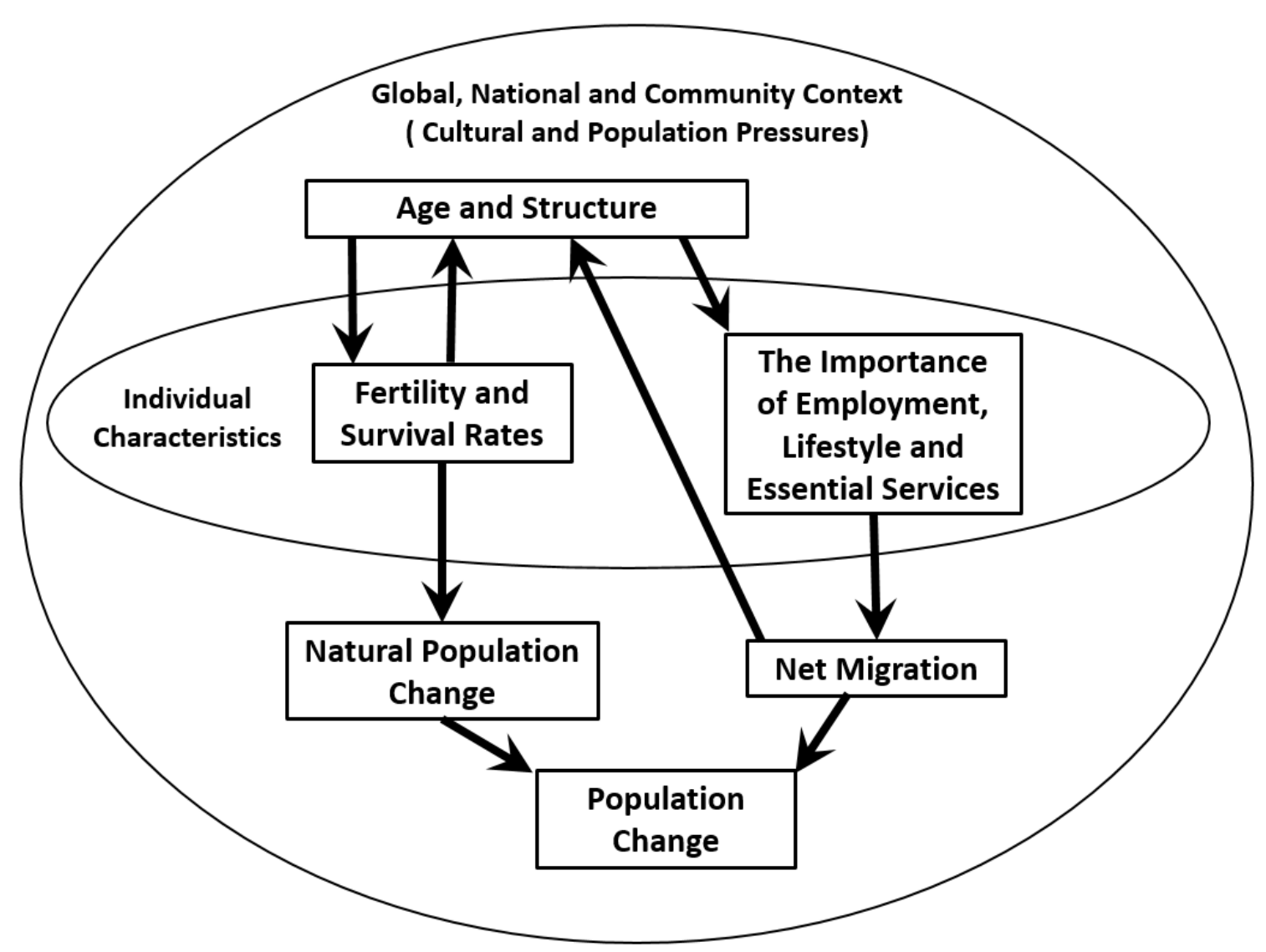

Figure 1 Conceptual diagram showing the general determinates of population change.

Population change is simply the sum of natural change (births minus deaths) and net migration (internal and international combined) between census periods (Figure 1). Feeding into that change, demographically, are fertility and survival rates and their interactions with age structure. While environmental and social factors also contribute to fertility and survivorship, here our focus is on their role as drivers of migration, working through age.

Births and deaths data (and thus natural change) for our 275 urban places for the period 19762013 are not available. Here we calculated them by modelling TA level fertility and survivorship rates and applying them to age and sex specific population counts for urban places from census data (see Jackson and Brabyn 2017 for more detail). Net migration by age was then calculated as a residual component by subtracting natural change by age from total change by age.

Figure 2 shows the resulting population change for every town in NZ, and the components of this change: natural change and net migration. These maps depict both relative change (using colour) and absolute change (using circle size). This paper provides an understanding of these components using the conceptual diagram in Figure 1 as a point of reference, before proposing that they are important considerations for regional development discussing the implications of these changes for regional development. The paper first asks the question; what is the relative importance of natural population change and net migration in determining total population change? It then asks whether net migration patterns are specific for selected 
age groups in New Zealand. This is followed by a GIS/machine-learning analysis to determine what are the relative influence of economic and lifestyle drivers of net migration by age. The final sections discuss how natural change, population ageing and net migration interact, and the implications of this research for sustainable regional development in New Zealand. Unless stated otherwise, all figures have been produced by the authors.

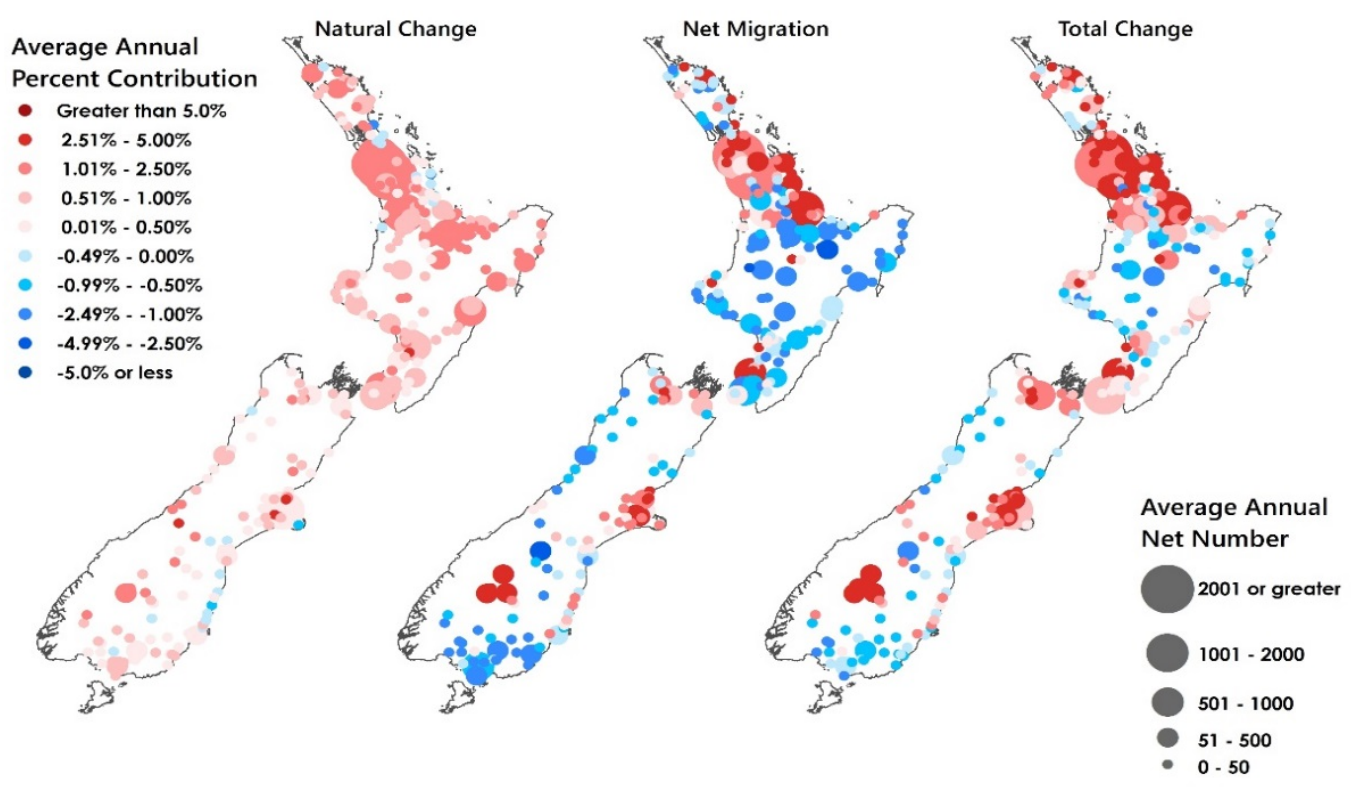

Figure 2 Comparison of natural change, net migration, and total change for New Zealand urban places between 1976 and 2013

\section{The drivers of population change are changing}

The link between population change and regional development is not an issue that is unique to New Zealand. However, the majority of literature focuses on population growth per se and its implications for funding and resources, especially that related to infrastructure. It largely conceptualises population growth as a potential 'given', responding to economic development, and seldom engages with underlying demographic change-New Zealand's current 'Grow Regions' Provincial Growth Fund project is one such example (MBIE 2018). A relatively small literature considers the role of changing age structures in driving subnational growth or decline, or the related prospect of permanent depopulation (e.g., Haartsen and Venhorst 2009; Matanle and Sato 2010; Matanle and Rausch 2011; Audirac 2012; Martinez-Fernandez, Kubo, Noya and Weyman 2012). Empirical evidence from these studies shows that structural ageing increasingly results in depopulation, as deaths come to exceed births, and migration-where positive-is increasingly insufficient to offset the gap. Depopulation is thus being driven by a 'new' and increasingly intractable set of dynamics: negative natural increase combining with the old form of population decline - net migration loss (Bucher and Mai 2005). The situation has been convincingly illustrated for the counties of the United States and Europe (Johnson, Field and Poston 2015; Murphy 2016). 
Analysing the situation for New Zealand, Jackson and Brabyn (2017) found that while subnational depopulation is as yet the result of net migration loss, the age profile of migrants is hastening the shift to hyper-ageing - currently defined as greater than 20 per cent aged 65+ years. A net loss of young people and/or gain of older people cause the population to grow older structurally, while a net gain of young people and/or loss of older people slow ageing. In 2013, 41 per cent of New Zealand towns, 29 per cent of rural centres, and 15 per cent of territorial authority areas already had greater than 20 per cent of their respective populations aged 65+ years (Jackson and Brabyn, 2017). These populations are approaching the end of their natural growth phase.

As a result of these dynamics, increasing numbers of territorial authority areas and the towns and centres which comprise them will see their growth slow or become negative, at the same time as the proportions at older ages soar. The ability of local bodies to raise rates when proportions aged 65+ years-mostly on fixed incomes-approach 30 and 40 per cent, will be seriously compromised, as will the ability of economic development to eternally 'grow the regions'. Rather, for many areas, such initiatives would be better directed at the opportunities arising from a potential 'depopulation dividend' (Matanle 2017). The opportunities arising from lower growth and likely depopulation need to be engaged with in a timely manner, long before local councils and similar agencies are overwhelmed with sustained depopulation that they have not been anticipating (Matanle and Sato 2010; Audirac 2012; Martinez-Fernandez, Kubo, Noya and Weyman 2012; McMillan 2016). It is therefore crucial that the focus of the relationship between population change and regional development shifts from the idea that growth is incessantly attainable, to population composition and the drivers of population change.

\section{The relative contribution of natural population change and net migration}

Understanding the relative contribution of natural change and net migration to total population change is important for strategizing a development plan for any particular place or region. For example, if a town's population is growing primarily from births then there needs to be a focus on families and early child-care, while if a town is growing from net migration by people of retirement age then there needs to be a focus on the needs and interests of older people, including aged care.

The maps in Figure 2 illustrate that spatial variation in the total population of each place is being driven by spatial variation in net migration. That is, an increase or decrease in total population vis-à-vis other areas will typically correspond to an increase or decrease in net migration. In contrast, natural change is almost universally positive, and while it may conceal underlying net migration loss or augment net migration gain, it is a common feature of both growing and declining areas - although this may not continue to be the case in the future, as discussed further below.

Supporting this claim, the graphs in Figures 3 respectively plot natural change versus total change, and net migration versus total change, for each place. These graphs illustrate that there is virtually no correlation between natural change and total change (Person's $r=0.05$ ) while there is strong correlation between net migration and total change (Person's $r=0.98$ ). 
These correlations show that net migration is more important in explaining the spatial variation in total population change.
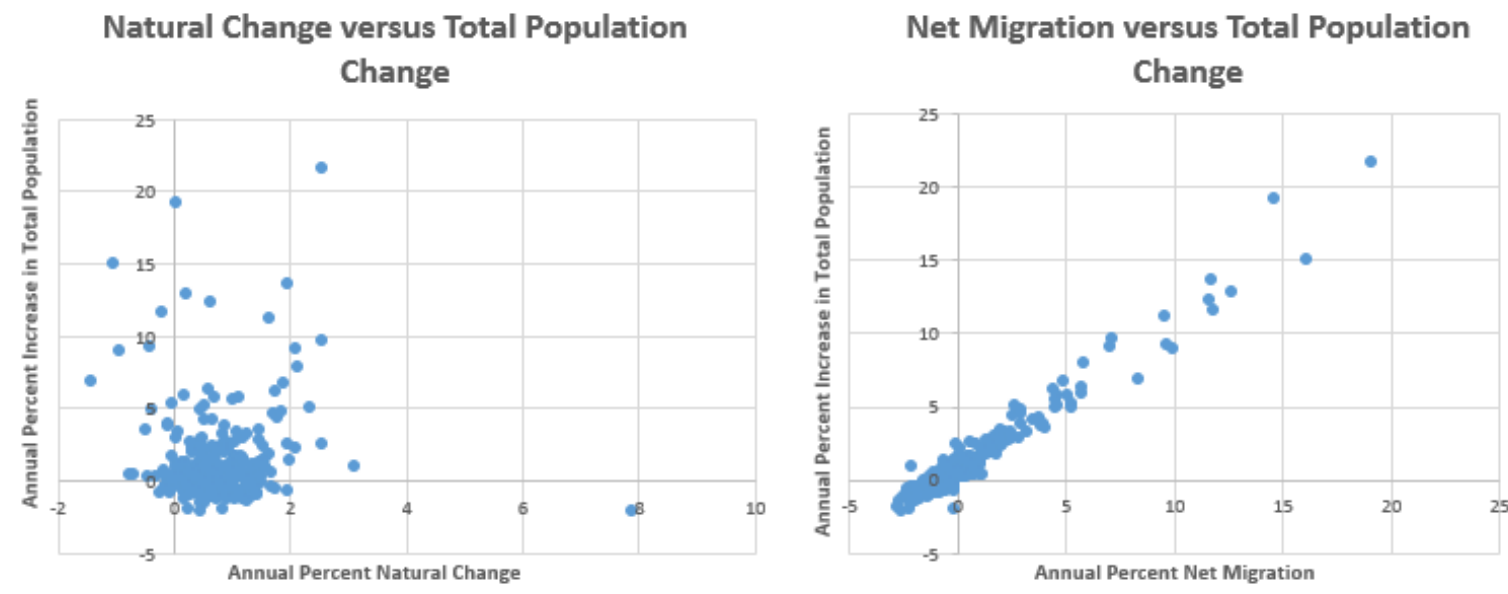

Figure 3 A comparison between annual percentage change in the main components of change and annual percentage change in total population (1976-2013)

As can also be seen from the lower left cells of the two panels in Figure 3, a small number of places experienced negative natural change (natural decrease) between 1976 and 2013 (n= 26), while a somewhat greater number experienced negative net migration $(n=163)$. For this reason, when the data are summed to gain a national level impression of their relative contribution to change, net migration makes a substantially lower contribution than natural increase-which is very misleading at the local level. Calculating the sum of their absolute values enables the two components to be meaningfully compared (Table 1). The relative contributions vary over time, but a fair summary is that, on average, natural change and net migration have contributed equally to the overall population change of urban places in New Zealand. However, as indicated, this picture is highly diverse at local level.

Table 1. Comparison of the contribution of natural change and net migration to total change (based on the sum of counts of all urban places in New Zealand)

\begin{tabular}{|l|r|r|r|r|r|}
\hline & $\begin{array}{c}\mathbf{1 9 7 6 -} \\
\mathbf{1 9 8 6}\end{array}$ & $\begin{array}{c}\mathbf{1 9 8 6}- \\
\mathbf{1 9 9 6}\end{array}$ & $\begin{array}{c}\mathbf{1 9 9 6 -} \\
\mathbf{2 0 0 6}\end{array}$ & $\begin{array}{c}\mathbf{2 0 0 6}- \\
\mathbf{2 0 1 3}\end{array}$ & $\begin{array}{c}\mathbf{1 9 7 6} \\
\mathbf{2 0 1 3}\end{array}$ \\
\hline Total Annual Natural Increase & 16292 & 21946 & 25757 & 28462 & $\mathbf{2 2 6 8 1}$ \\
\hline Total Annual Net Migration & -622 & 9905 & 11595 & -2479 & $\mathbf{5 1 7 5}$ \\
\hline Total Annual Population Change & 15670 & 31851 & 37352 & 25983 & $\mathbf{2 7 8 5 6}$ \\
\hline Total Annual Absolute Natural Increase & 16557 & 22063 & 25946 & 28879 & $\mathbf{2 2 8 0 6}$ \\
\hline Total Annual Absolute Net Migration & 20116 & 27991 & 29174 & 19148 & $\mathbf{2 0 1 9 7}$ \\
\hline Total Annual Absolute Population Change & 36673 & 50054 & 55120 & 48027 & $\mathbf{4 3 0 0 3}$ \\
\hline $\begin{array}{l}\text { Annual Absolute Natural Increase as a \% of } \\
\text { Base Population }\end{array}$ & 0.61 & 0.77 & 0.82 & 0.81 & $\mathbf{0 . 8 4}$ \\
\hline $\begin{array}{l}\text { Annual Absolute Net Migration as a \% of } \\
\text { Base Population }\end{array}$ & 0.75 & 0.98 & 0.92 & 0.54 & $\mathbf{0 . 7 5}$ \\
\hline
\end{tabular}


Natural Increase to Net Migration Ratio using the Absolute Contribution of Components

0.82

$0.79|0.89|$

* This is a seven-year period. The Christchurch earthquake delayed the 2011 population census to 2013. Note that 2018 census data were not available for this research at the time of publication in 2019.

The New Zealand Atlas of Population Change provides individual graphs for each urban place, so that users can see how natural change and net migration contribute to total population change. Figure 4 and 5 provide examples of two places where the combination of components have very different profiles: Tauranga City and Auckland. For Tauranga City (Figure 4), the main component of growth has been net migration, while for Auckland, except for a few periods (eg 2001-2003 and 2013-18), it has been natural increase.

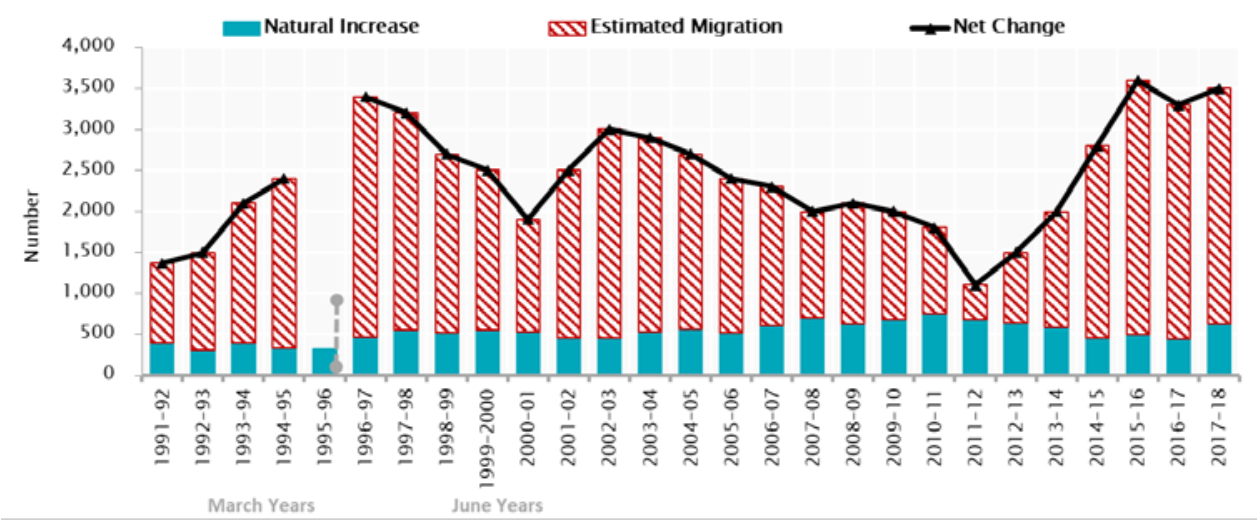

Source: Jackson and Pawar 2014-2019

Figure 4 Contribution of natural change and net migration to total change, Tauranga City (1991-2018)

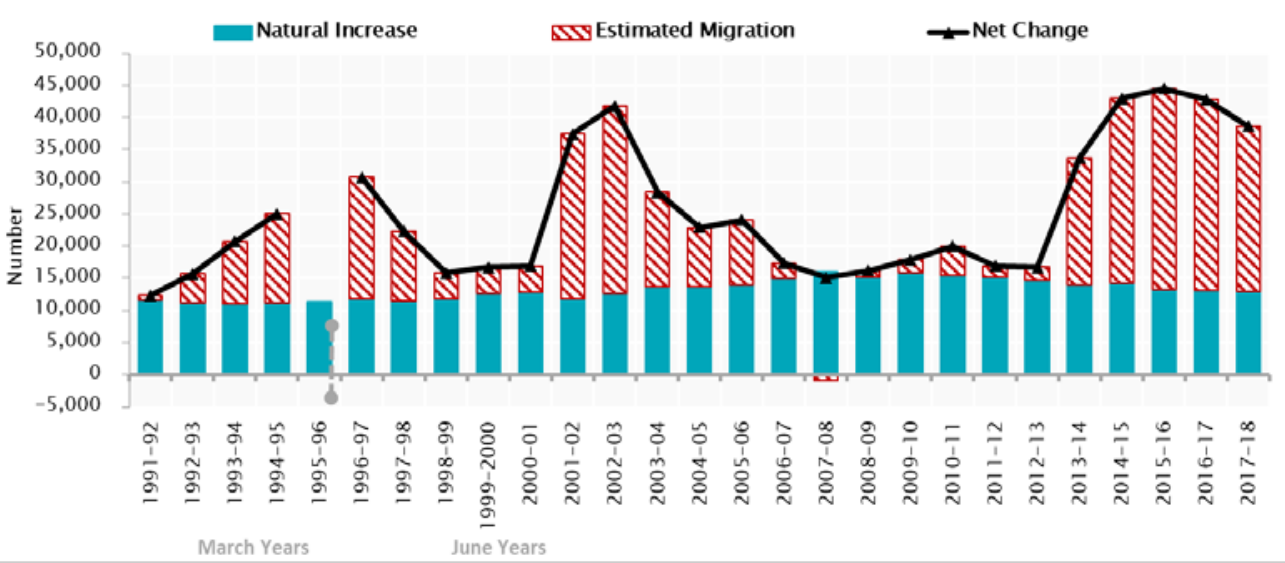

Source: Jackson and Pawar 2014-2019 
Figure 5 Contribution of natural change and net migration to total change, Auckland (19912018)

\section{The contribution of net migration by age}

Understanding the role of migration in contributing to population change requires a shift in thinking from migration per se, to migrants in terms of age (and sex, but we do not deal with that here) and life stage. Figures 6, 7, and 8 show the contribution of net migration to change at each age for New Zealand urban places over the four decades 1976-2013, for people at 1524 years (labour market entry age), 20-64 years (prime working age group) and 65+ years ('retirement age') respectively (for other age groups see socialatlas.waikato.ac.nz). Net migration here is the combined result of internal migration within New Zealand as well as international migration - which would ideally be separated for future analysis because internal and international migrants differ by both age and in terms of their reproductive and survivorship characteristics.

The spatial patterns of net migration for those aged 15-24 years in Figure 6 are highly consistent across the four decades. The vast majority of places have consistently experienced notable net loss (greater than 5 per cent) of young people, and just a few places-mainly cities and tourist destinations, have gained them. At the prime working ages, 20-64 years (Figure 7), there are fewer areas of loss and more of gain, and the losses are not so pronounced-there is also a strong south-north gradient (and a notable net loss between 2006 and 2013 around the Christchurch area, reflecting the Canterbury earthquakes of 2010-11). At 65+ years (Figure 8), losses and gains are similarly spread spatially, but are generally less pronounced again. There are sustained net losses for Wellington across all periods, and for Auckland since 1996, but increasing gains for coastal and warmer ('sun-belt') areas.

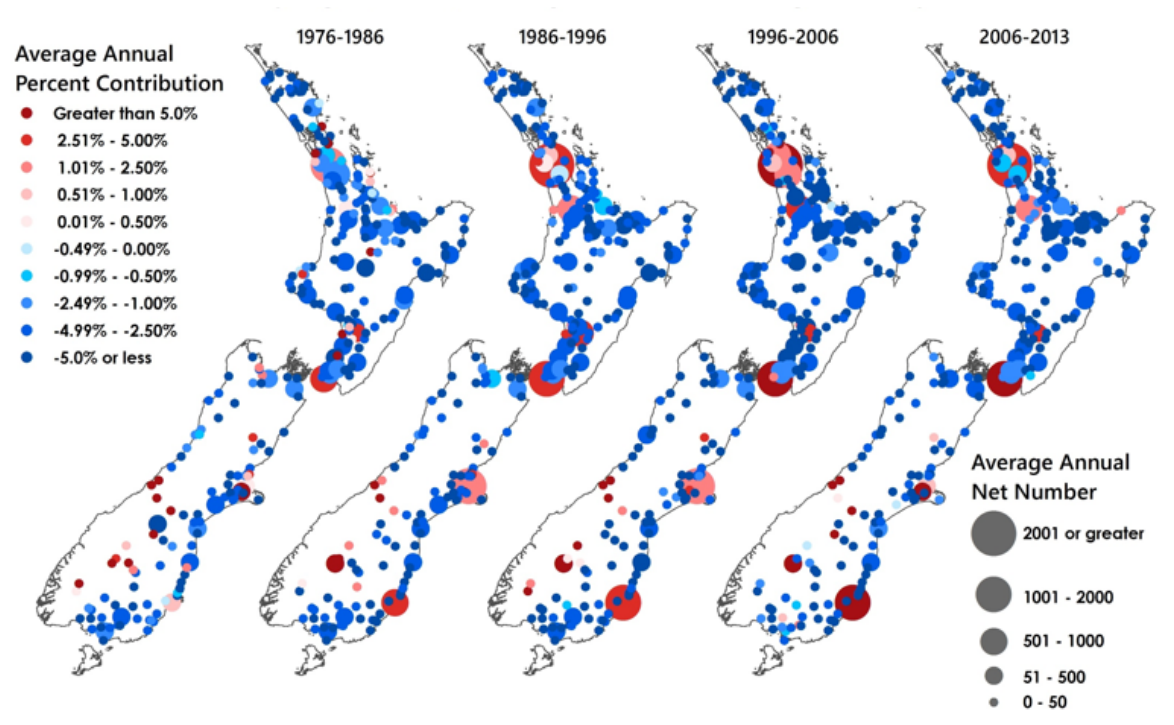

Figure 6 Average annual net migration at 15-24 years (\% of age group) by decade, 19762013 




Figure 7 Average annual net migration at 20-64 years (\% of age group) by decade, 19762013

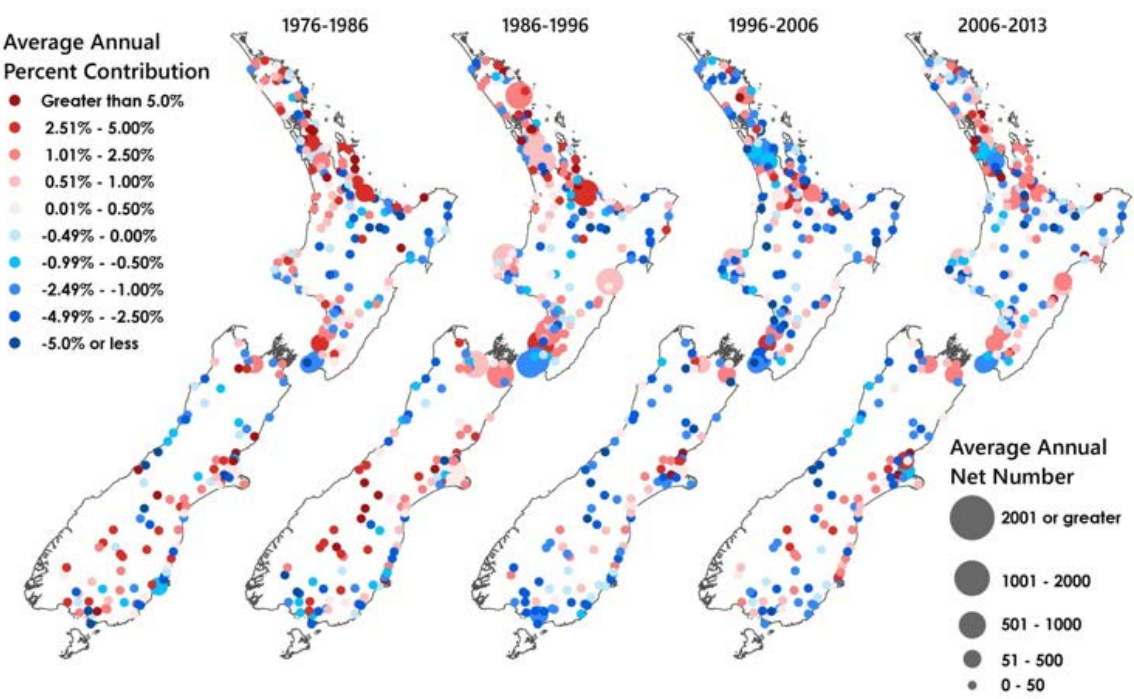

Figure 8 Average annual net migration at 65+ years (\% of age group) by decade, 1976-2013

There have been both qualitative and quantitative studies in New Zealand that have asked why people move to different places, and what characteristics attract people. There is reasonable consistency in the results between these methods. Among others, Morrison and Clark (2011) used data from the Survey of Dynamics of Motivation and Migration, which recorded in detail why over 6000 individuals moved within NZ during the 2005 and 2006 period. This survey showed that employment was not the main motivator, and that education, environment, housing costs and social considerations were also important. 
A major quantitative project by Brabyn (2017) combined the data visualised in Figures 6, 7, and 8 (plus data from other age groups) with GIS derived data, such as airports, landcover (Newsome, 1987), hospitals (Brabyn and Skelly, 2002), and the NZ Landscape Classification (Brabyn, 2009). Each urban place was characterised in relation to the surrounding land-use and landscape (nature, mountains and coastline), access (travel time) to airports (regional and international), ports, large cities, universities, polytechnics, hospitals (tertiary and secondary), and climate. A range of GIS analysis tools were used such as network, proximity, and overlay analysis. With such a large data set, collinearity between variables prevents regression models from working, even when dimensionality reduction techniques such as principal component analysis are used. Machine learning techniques that rely on iterative trial and error processing provide solutions that are not prone to the problems associated with regressions (Cutler et al., 2007; Rodriguez-Galiano et al., 2012; Breiman, 2001). The Random Forest module in $\mathrm{R}$ (open source statistical package) was used to identify which variables are the most important in explaining net migration to the 275 places. This technique evaluates hundreds (500 for this study) of randomly produced decision trees against a validation sample (known as bootstrap sampling) to rank the importance of each explanatory variable (Poulos and Camp, 2010).

Table 2 provides the results from the machine learning and validates what can be seen in Figures 6, 7, and 8. Population age is by far the most important variable explaining net migration patterns. Young people are attracted to larger population centres with universities and polytechnics (and life-stage attractions more generally). They are also attracted to urban places that are surrounded by nature, which is characteristic of many popular tourism destinations. This younger group is also tolerant of high rainfall urban places. These results are contradictive because many tourism urban places have small populations. They reflect the complex nature of modelling human movements, and are why, even with machine learning, only $43 \%$ of the variation can be explained for younger people. However, it is a start, and is consistent with a lower model performance for the prime working age and the retirement age groups, at $41 \%$ and $8 \%$ respectively. As was shown in Figures 7 , and 8 , the spatial variability of these age groups is somewhat more diverse than that for the 15-24 year age group. 
Table 2. Summary of key drivers of net migration by age group

\begin{tabular}{|c|c|c|c|c|c|c|c|c|c|c|c|c|c|c|c|}
\hline \multirow[t]{2}{*}{$\begin{array}{c}\text { Dependant } \\
\text { Variable }\end{array}$} & \multicolumn{3}{|c|}{ All Age Groups } & \multicolumn{3}{|c|}{$\begin{array}{c}\text { Labour Market Entry Age } \\
15 \text { to } 24 \text { years }\end{array}$} & \multicolumn{3}{|c|}{$\begin{array}{l}\text { Prime Working Age } \\
24 \text { to } 54 \text { years }\end{array}$} & \multicolumn{3}{|c|}{$\begin{array}{c}\text { Labour Market Exit Age } \\
55 \text { to } 64 \text { years }\end{array}$} & \multicolumn{3}{|c|}{$\begin{array}{r}\text { Retirement Age } \\
65+\text { years }\end{array}$} \\
\hline & & $\mathrm{RI}$ & $\rho$ & & RI & $\rho$ & & RI & $\rho$ & & $\mathrm{RI}$ & $\rho$ & & RI & $\rho$ \\
\hline \multirow{10}{*}{$\begin{array}{c}\text { Top } 10 \\
\text { explanatory } \\
\text { Variables } \\
\text { Listed by } \\
\text { Order of } \\
\text { Importance }\end{array}$} & Entry Age 15-24 & 1.00 & -0.35 & Population Size & 1.00 & 0.31 & Population Size & 1.00 & -0.05 & Population Size & 1.00 & -0.11 & Population Size & 1.00 & 0.02 \\
\hline & Exit Age 55-64 & 0.99 & 0.46 & Temperature & 0.92 & -0.40 & Water View & 0.53 & 0.40 & Water View & 0.86 & 0.38 & Time to an Int. Airport & 0.69 & -0.25 \\
\hline & Mountains & 0.65 & 0.04 & Time to Pop. $>50 \mathrm{k}$ & 0.92 & 0.05 & Hills & 0.36 & -0.31 & Hills & 0.53 & -0.19 & Time to Pop. $>200 \mathrm{k}$ & 0.56 & -0.24 \\
\hline & Population Size & 0.62 & -0.03 & Natural Land & 0.89 & 0.25 & Mountains & 0.30 & 0.05 & Solar Radiation & 0.52 & 0.15 & Low Producing Land & 0.45 & -0.15 \\
\hline & Retire Age 65 + & 0.57 & 0.36 & Time to a Hospital & 0.88 & 0.05 & Solar Radiation & 0.27 & 0.19 & Temperature & 0.49 & 0.15 & Temperature & 0.40 & 0.20 \\
\hline & Hills & 0.43 & -0.32 & Hills & 0.89 & -0.20 & Coastline & 0.25 & 0.30 & Time to an Int. Airport & 0.49 & -0.21 & Coastline & 0.38 & 0.20 \\
\hline & Working Age 20-64 & 0.37 & 0.27 & Rainfall & 0.88 & 0.10 & Natural Land & 0.21 & -0.03 & Low Producing Land & 0.48 & -0.03 & Time to a Major Hospital & 0.37 & -0.20 \\
\hline & Coastline & 0.33 & 0.32 & Time to a University & 0.87 & -0.04 & Temperature & 0.20 & 0.17 & Rainfall & 0.48 & -0.10 & Time to Large Port & 0.32 & -0.08 \\
\hline & Solar Radiation & 0.31 & 0.20 & Time to Pop. $>$ 20k & 0.73 & 0.13 & Time to a Hospital & 0.20 & 0.13 & Time to a Hospital & 0.39 & 0.13 & Hills & 0.30 & -0.11 \\
\hline & $\begin{array}{l}\text { Time to an Int. } \\
\text { Airport }\end{array}$ & 0.28 & -0.31 & Tertiary Education & 0.60 & $0-00$ & Low Producing Land & 0.18 & -0.04 & Mountains & 0.39 & 0.05 & Time to an Airport & 0.30 & -0.15 \\
\hline $\begin{array}{l}\text { Variability } \\
\text { Explained }\end{array}$ & 0.47 & & & 0.43 & & & 0.41 & & & 0.24 & & & 0.08 & & \\
\hline
\end{tabular}

$R I=$ relative importance, which is a ranking between 1 and 0 of the importance values generated by Random Forest

$P=$ Pearson's correlation coefficient, which is used to identify the direction of the importance (negative or positive).

NB. Travel times to services are expected to have a negative influence as people prefer to have less travel time. 
Also consistent with Figures 6-8 above, Table 2 shows that the population size of an urban place has an important influence on net migration, but the direction of influence varies by age group. Population size has a positive influence on the labour market entry (Figure 6) and a negative influence on those at labour market 'exit age', 55-64 years. However, closeness to larger cities is important for those aged 65+ years (see Figure 8). Again, there are logical explanations for these results. Large cities have job opportunities, but when people reach retirement age, many are thinking about lifestyle in smaller communities. At the same time, within the 65+ age group, needs often change as age advances. For older people in particular, closeness to hospitals located in cities becomes important. Breaking the older age group down into 'young old' and 'older-old' would be important for future research, for a more nuanced understanding.

Table 2 also shows that lifestyle variables (temperature, solar radiation, mountains, and coast) are just as important as economic variables, for all age groups. Access to international airports is also important, which can be regarded as both a lifestyle variable (overseas holidays) and an economic variable (access to markets).

Hills (as opposed to mountains) show up as having a high negative influence for all age groups. Most hill country in NZ is used for sheep farming, therefore urban places surrounded by hills are also surrounded by sheep farms. Communities dependent on business for sheep farms are declining (primarily) due to negative net migration. The reasons for this are not part of this research but are linked to corporatization and the mechanisation of farms (Greig Nuthall and Old, 2019). The results show that low producing land-use, which includes both sheep farming and forestry, also has a negative influence on net migration.

\section{The contribution of internal and international migration}

International net migration to NZ can have a major influence on the net migration of urban places in NZ. Figure 9 shows that international net migration has fluctuated considerably and is therefore difficult to predict. For the period 1991 to 2013 the average net migration was 11,961 , while if 2013-2018 is also included the average is 21,439 . We have not analysed the separate impacts of internal and international migration on our 275 urban places, because such data are not available. However, Figure 10 shows that, at Territorial Authority Area (TA) level, internal migration gains and losses are (typically) more diverse geographically than international migration gains, and this will undoubtedly hold true for the urban places that comprise these TAs. Moreover, many TAs simultaneously experience net internal gain and net international loss—while just a few experience the opposite. As indicated above, these flows also differ by age. Future research on interactions between the components of change and local population change will be enhanced by separating the two migration sources. For now, it should be assumed that the findings in Table 2 will differ by source. 




Figure 9 Contribution of natural change and international net migration to total change, New Zealand

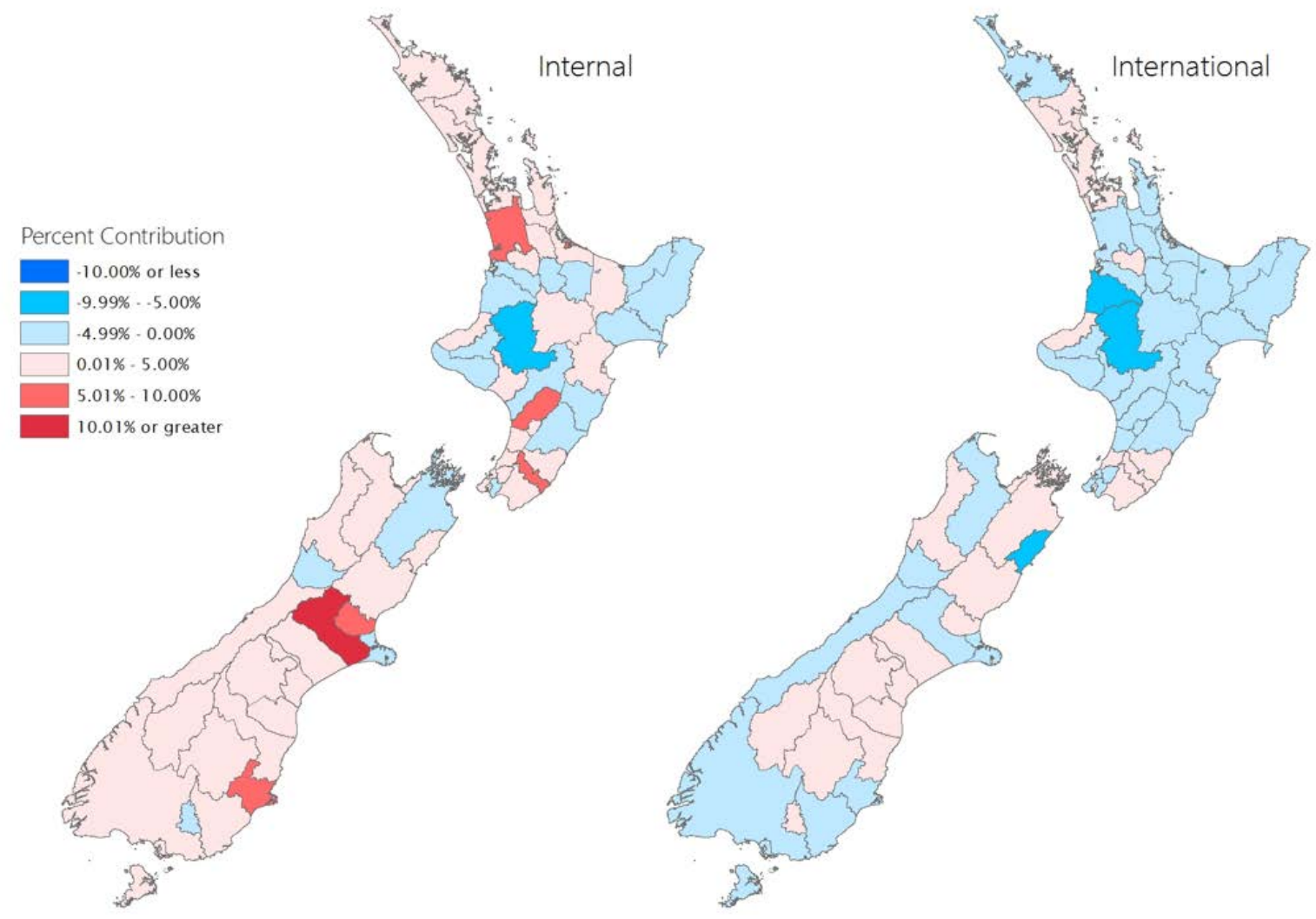

Figure 10 Contribution of internal and international net migration to total net migration by territorial authority area (2008-2013)

6 The interaction of natural change, population ageing, and net migration 
As discussed in the earlier section, the relationship between natural population change and population ageing has been widely studied, although typically the focus is natural increase or decrease (the difference between births and deaths) and its implications for population growth. Complementing this work, our research has also examined natural change occurring across the age structure, as birth cohorts age and replace smaller or larger cohorts ahead of them—and others move in behind them (Jackson Brabyn Maré Cameron and Pool, 2019). These wave-like movements are in many cases exacerbated by in- and out-migration at the subnational level. Diminishing cohort size among many young age groups due to declining birth rates is often further depleted by net migration loss, especially around 15-24 years of age, as was indicated in Figure 6 above, while increasing cohort size at older ages - currently reflecting the movement of baby boomers through the age structure (Figure 11) -is often amplified by the net migration gain of 'retirees' (Figure 8). Together these dynamics accelerate both structural and numerical ageing (structural ageing being the increase in proportion at older ages; numerical ageing being the increase in older numbers).

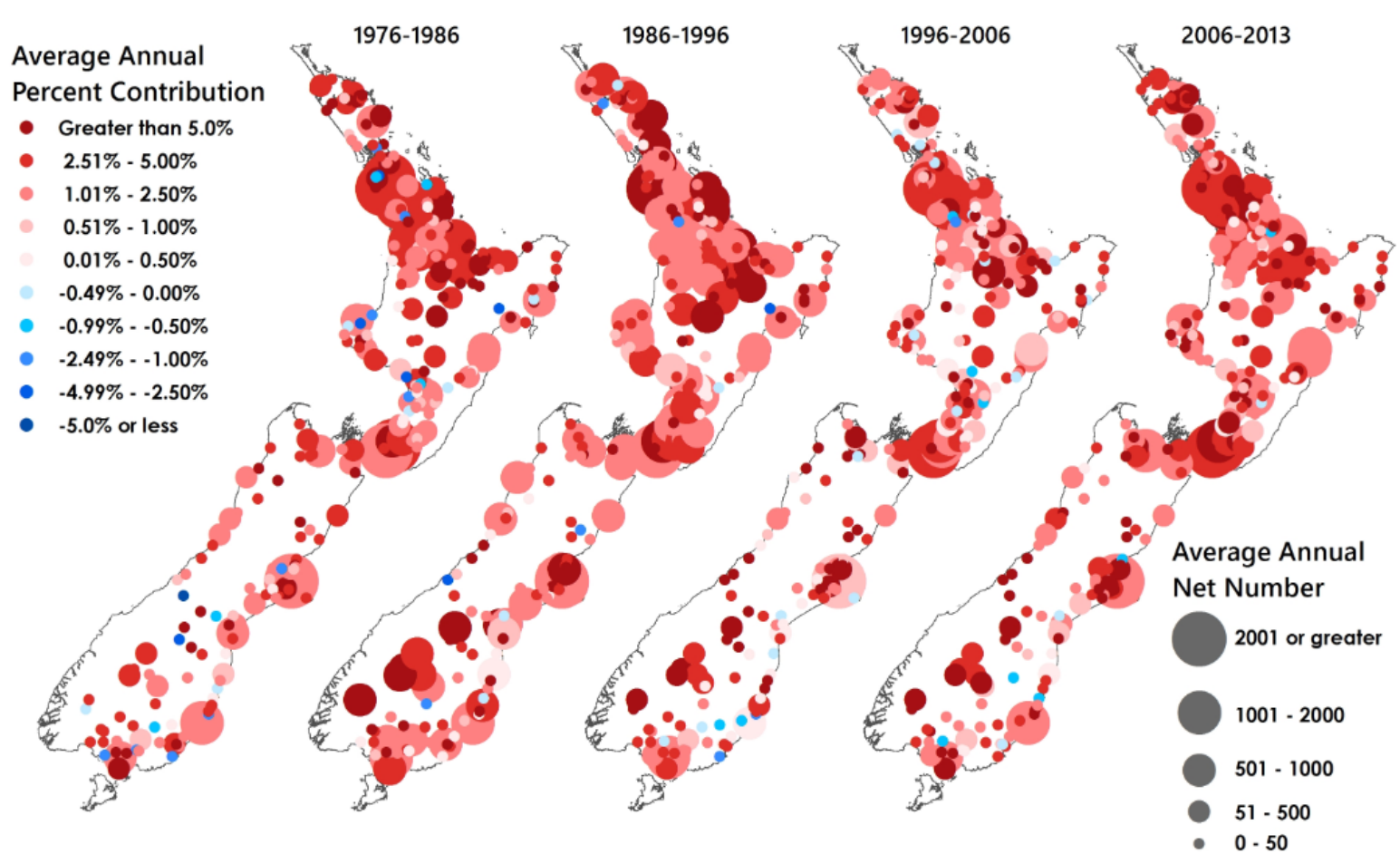

Figure 11 Average natural change at 65+ years (\% of age group) by decade (1976-2013)

The fact that migration can accelerate underlying population ageing (Jackson and Cameron 2018) has been largely_and detrimentally_overlooked; instead, a general perception that 'migration keeps populations young' has for many years filtered through government and local body mantra and policy. The migration that has this potential is primarily international migration, because the vast majority of movers are between 20 and 40 years of age, and, like young internal movers, typically head for the same destinations, where they indeed expand the relative youthfulness of those areas. But as Figure 7 above indicates, for New Zealand these areas are few, pertaining almost exclusively to major cities and tourist spots. At the opposite end of the age spectrum, net migration gains at older ages are concentrated in coastal 
and lifestyle/amenity destinations (Figure 8), where they add to numbers and proportions at older ages - and of course, no longer add children to balance the base of the age structure. As Jackson and Brabyn (2017) found, only 15 per cent of New Zealand towns and one-third of rural centres became structurally younger as the result of migration between 1976 and 2013; the vast majority became structurally older.

These migration-ageing interactions have another slowly unfolding consequence-the emerging end of natural increase and onset of natural decrease-following which migration will become the only driver of population change across a wide expanse of New Zealand. At present, only three territorial areas are experiencing natural decrease (Figure 12); however, with 41 per cent of towns and 29 per cent of rural centres already having greater than 20 per cent aged 65+ years in 2013 (Jackson and Brabyn 2017), natural decrease is on the horizon. Between 2028 and 2033, around one-quarter of territorial authority areas will see the onset of natural decrease, and between 2038 and 2043, around 60 per cent. This shift will leave affected areas highly vulnerable to depopulation, as those which experience net migration loss will have no natural increase component to protect them.



Figure 12 Projected natural increase/decrease by territorial authority area (2018-2043), medium variant

The interactions between migration, age structure, and population ageing briefly described above are by no means limited to New Zealand, or a quirk of the country's relatively high international migration flows or the local mobility of New Zealanders. In the global demographic literature, the past focus on population size and its drivers is slowly giving way to the study of population composition, and increasingly to subnational composition and depopulation (Bucher and Mai 2005; Haartsen and Venhorst 2009; Matanle and Sato 2010; 
Matanle and Rausch 2011; Audirac 2012; Martinez-Fernandez, Kubo, Noya and Weyman 2012; Johnson, Field and Poston 2015; Murphy 2016). It is only slowly that the intractable and self-reinforcing nature of the interaction between migration and ageing is becoming acknowledged, alongside awareness that increasing international migration of working age people will be required to offset spiralling decline in many places (United Nations 2000; World Bank 2009; Lee and Reher 2011). However, as the demographic and mobility transitions proceed, the pool of 'desirable' migrants - typically, those with skills or business acumen-will undoubtedly be faced with competition from other countries with ageing populations, among which New Zealand is at the younger end. Countries and regions which therefore have a nuanced understanding of these circumstances will be better placed to attract migrants, both international and local, or positively embrace population stability (Matanle 2017; see McMillan 2016 for a review of international literature).

\section{Discussion and implications for sustainable regional development in New Zealand}

An understanding of population change at the urban level is helpful for strategizing responses for places and regions whether they are growing or declining. This research has outlined the relative contributions that natural change and net migration have on population change at the urban level. The results show that there has been an approximately equal contribution of these two components at the national level, but spatially, the patterns are highly diverse. Natural change (births minus deaths) is mostly positive across New Zealand's urban places, while net migration varies significantly, especially by age. A net gain of older migrants can offset a net loss of younger migrants to deliver overall net migration gain, and vice-versa. Natural increase may offset or conceal underlying net migration loss, or augment net migration gain or loss, to deliver overall growth or decline. The ageing of the 'base' age structure of both origin and destination populations can be slowed or accelerated by these flows and patterns, with implications for future growth.

Current and projected fertility and survival rates in New Zealand mean that the proportion of the population that is old will increase, and deaths will slowly overtake births. In two decades, natural change is projected to be negative across 60 per cent of New Zealand's territorial authority areas. These changes are inevitable because, as elsewhere in the developed world, fertility rates are below the level needed for population replacement and are unlikely to increase significantly. The greater the proportion of older people, the more deaths will exceed births. Town and even cities will have to accept that they will experience natural decrease, and in many cases, also depopulation, as the 'protection' long offered by natural increase will be gone. Councils and organisations will need to plan accordingly.

Migration is the only component of population change that policy (in a developed country) can have any significant influence on. There are many policies that respond to natural change and population ageing but there are few that have successfully influenced these trends. In contrast, there are many policies that both influence and respond to migration. As natural change reduces, migration will become increasingly vital to urban places - assuming they desire growth. For urban places that want to attract more people through migration, careful consideration will need to be given to the characteristics of the town and the surrounding region. This research has identified some of the preferences that people have when choosing a place to live, and how these preferences vary for different age groups. Development and 
marketing plans for growth need to identify which age group/s a place is likely to attract based on access to essential services, airports, and education, as well as the surrounding landscape and land-use. Many small urban places have the advantage that small population size is an attractive option for the 55+ year age groups. At the same time, urban places close to international airports, hospitals and large cities are shown to have an additional advantage for these age groups.

Many of the determinants of net migration are, however, largely outside the control of local communities and require a central Government response. Access to an international airport has an important influence on net migration; the development of the Queenstown International Airport has demonstrated this, yet the construction of an international airport is not a feasible option for every large town. If Taupo, for example, had an international airport — or was more effectively serviced by local carriers - it is likely that there would be increased migration to the central North Island region and many small towns in the area would grow in population. Equally, efficient regional airports that provide gateways to international services offset the need for many international airports. Access to essential health services and tertiary education have similar impacts. While all these services require a critical population size, because there are gains from economies of scale, the need for geographical access may also be negated by the use of the internet, which will improve access to health and education through virtual consultations and classes. The key message is that net migration is and will become ever-more important for regional development because of forthcoming natural population decrease. No doubt there will always be places that are more favourable to live than other places, and this will continue to result in regional disparities. If a place wants to attract people, careful consideration needs to be given to the economic, lifestyle and infrastructure characteristics of the place and the age group that these characteristics will be attracted to.

\section{References}

Audirac, I. (2012) Declining suburbs in Europe and Latin America. International Journal of Urban and Regional Research 36, 226-244.

Brabyn, L., \& Skelly, C. (2002) Modeling population access to New Zealand public hospitals. International Journal of Health Geographics 1,3.

Brabyn, L. (2009) Classifying landscape character. Landscape Research 34, 299-321.

Brabyn, L. (2017) Declining Towns and Rapidly Growing Cities in New Zealand developing an empirically-based model that can inform policy. Policy Quarterly 13, 37-46.

Breiman, L. (2001) Random forests. Machine Learning 45, 5-32.

Bucher, H., \& Mai, R. (2005) Depopulation and its Consequences for the Regions of Europe. Report Prepared for the Council of Europe, Directorate General III-Social Cohesion DG3/CAHP10(2005) 7.

Cutler, D. R., Edwards, T. C., Beard, K. H., Cutler, A., Hess, K. T., Gibson, J., \& Lawler J. J. (2007) Random Forests for Classification in Ecology. Ecology 88, 2783-2792. 
Equab, S. (2014) NZ has zombie towns that need to close - economist. National Business Review 12 July, https:/www.nbr.co.nz/article/nz-has-zombie-towns-needclose-\%E2\%80\%94-economist-ns-159124 (retrieved 20 May 2019).

Greig, B., Nuthall, P., \& Old, K. (2019) Resilience and finances on Aotearoa New Zealand farms: Evidence from a random survey on the sources and uses of debt. New Zealand Geographer 75 21-33.

Hagget, P. (1983) Geography. A Modern Synthesis. New York: Harper \& Row.

Haartsen, T., \& Venhorst, V. (2009) Planning for decline: anticipating on population decline in the Netherlands. Econom. en Social Geography 101, 218-227.

Jackson, N. O. (2016) Irresistible forces: facing up to demographic change. In P. Spoonley (ed.). Rebooting the Regions. Why low or zero growth needn't mean the end of prosperity. Auckland: Massey University Press: 47-77.

Jackson, N. O., \& Brabyn, L. (2017) The mechanisms of subnational population growth and decline in New Zealand, 1976-2013. Policy Quarterly Supplement 13: 22-36.

Jackson, N. O., Brabyn, L., Maré, D., Cameron, M. P. \& Pool, I. (2019) From ageing-driven growth towards the ending of growth. Subnational population trends in New Zealand, in J Anson, W., Bartl, A., \& Kulczycki (Eds.) Studies in the Sociology of Population. International Perspectives. Switzerland: Springer Nature: 161-193. https://doi.org/10.1007/978-3-319-94869-0

Jackson, N. O., \& Cameron, M. P. (2018) The unavoidable nature of population ageing and the ageing-driven end of growth - an update for New Zealand. Population Ageing 11, 239264.

Jackson, N. O., \& Pawar, S. (2014-2019) A subnational demographic accounting model for New Zealand, digital resource originally developed for Nga Tangata Oho Mairangi (Population change and its implications for New Zealand's communities), Funded by the Ministry of Business, Innovation and Employment (MBIE) 2011-2014, National Institute of Demographic and Economic Analysis, University of Waikato.

Johnson, K. M., Field, L. M., \& Poston, Jnr. D. L. (2015) More deaths than births: subnational natural decrease in Europe and the United States. Population and Development Review 41, 651-680.

Lee, R. D., \& Reher, D. S. (2011) Introduction: The Landscape of the Demographic Transition and its Aftermath. Population and Development Review 37, 1-7.

Martinez-Fernandez, C., Kubo, N., Noya, A., \& Weyman, T. (2012) Demographic change and local development: shrinkage, regeneration and social dynamics OECD/LEED Working Paper Series.

Matanle, P. (2017) Towards an Asia-Pacific depopulation dividend in the $21^{\text {st }}$ Century.

Regional growth and shrinkage in Japan and New Zealand. The Asia-Pacific Journal 155.

Matanle, P., \& Rausch, A. (2011) Japan's Shrinking Regions in the 21st Century:

Contemporary responses to depopulation and socioeconomic decline. Amherst, NY: Cambria Press.

Matanle, P., \& Sato, Y. (2010) 'Coming soon to a city near you! Learning to live 'beyond growth’ in Japan’s shrinking regions’ Social Science Japan Journal 13 187-210. 
McMillan, R. (2016) The shrinkage pathway: managing regional depopulation. In: Spoonley P (ed) Rebooting the Regions: How low or zero growth needn't mean the end of prosperity, Albany: Massey University Press. pp 213-237.

MBIE (Ministry of Business, Innovation and Employment) (2018) Grow Regions.

https://www.growregions.govt.nz/

Morrison, P. S., \& Clark, W. A. V. (2011) Internal Migration and Employment: Macro Flows and Micro Motives. 43, 8.

Murphy, M. (2016) The impact of migration on long-term European population trends, 1850 to present. Population and Development Review 42, 225-244.

Newsome, P. (1987) The vegetation cover of New Zealand. Ministry of Works and Development.

Poulos, H., \& Camp, A. (2010) Decision support for mitigating the risk of tree induced transmission line failure in utility rights-of-way. Environmental Management 45, 217-226.

Rodriguez-Galiano, V. F., Ghimire, B., Rogan, J., Chica-Olmo, M., \& Rigol-Sanchez, J P (2012) An assessment of the effectiveness of a random forest classifier for land-cover classification. ISPRS Journal of Photogrammetry and Remote Sensing 67, 93-104.

Statistics New Zealand (2019) Defining Urban and Rural New Zealand.

http://archive.stats.govt.nz/browse for stats/Maps and geography/Geographic-areas/urban-ruralprofile/defining-urban-rural-nz.aspx

United Nations (2000) Replacement Migration. Is it a solution to declining or ageing populations? UN Secretariat, Department of Economic and Social Affairs.

World Bank (2009) Reshaping Economic Geography. Washington DC: World Bank.

\footnotetext{
' http://archive.stats.govt.nz/Census/2013-census/info-about-2013-census-data/2013-censusdefinitions-forms/definitions/geographic.aspx
}

\footnotetext{
ii Acknowledgement: Access to the data used for modelling was provided by Statistics New Zealand under conditions designed to give effect to the security and confidentiality provisions of the Statistics Act 1975 . The results and any errors are the work of the author/s, not Statistics New Zealand. Data from the 2018 census was not availablefor this research as of September 2019.
} 